\title{
La formación intelectual y eclesiástica de los ministros ordenados en la Iglesia Occidental en el siglo $\mathrm{V}$
}

\author{
Marcelo Alcayaga \\ SAN JUAN, ARGENTINA
}

En consonancia con el tema propuesto para el presente Seminario de Estudios Patrísticos: La relación entre razón y revelación en la reflexión patrística, este trabajo pone de manifiesto cómo esta conjunción se daba específicamente en la formación exigida a los presbíteros encargados de las comunidades cristianas en la era patrística. En efecto, la misma constaba de una parte basada en los conocimientos intelectuales propios de la época y de otra parte constituida por una formación específicamente eclesiástica. Para esta investigación se toman como parámetro espacio temporal a la Iglesia Occidental, en el siglo V.

El trabajo se articula en tres partes: la primera muestra cómo, en el siglo $\mathrm{V}$, la formación intelectual era un requisito ya tradicionalmente exigido a los candidatos al ministerio ordenado, la segunda expone cuáles eran los estudios humanísticos que ellos podían realizar en su tiempo y la tercera trata sobre la formación eminentemente sacerdotal que los preparaba para desempeñar su ministerio en las comunidades que se les confiaban.

\section{La formación, requisito indispensable en los clérigos}

En la Iglesia de Occidente, al menos desde el siglo IV, la formación intelectual era un requisito indispensable exigido a los clérigos ya que ellos tenían la misión de adoctrinar y guiar a las comunidades, de proclamar las sagradas Escrituras, de leer los libros rituales y otras acciones que precisaban una debida instrucción ${ }^{1}$.

\footnotetext{
Cf. A. Fatvre, Naissance d'une hiérarchie. Les premières étapes du cursus clérical (Paris 1977)
} 316; V. Grossi - A. Di Berardino, La chiesa antica: ecclesiologia e istituzioni (Roma 1984) 
A este respecto, algunas disposiciones disciplinares del siglo IV piden la formación intelectual en los clérigos (en África el concilio de Cartago del 397² en las Galias los Statuta ecclesiae antiqua ${ }^{3}$; en Roma el sínodo del $465^{4}$ ). Varios papas del siglo $V$ reiterarán en ciertos decretos la necesidad de la formación para conferir el orden; esto se encuentra, por ejemplo, de Zósimo (417-418) $)^{5}$, Celestino (422-432) ${ }^{6}$, León Magno (440-461) $)^{7}$, Hilario (461-468) $)^{8}$, Gelasio (492-496) ${ }^{9}$.

87; J. Gaudemet, L'Eglise dans l'empire romain (IV-VI siècles) (Paris 1958, mise à jour 1989) 135.

2 Breviarium Hipponense cc. 1c y 2 (CCL 149, 33) 1c.Ut primum scripturis divinis instructi vel ab infantia eruditi, propter fidei professionem et assertionem, clerici promoveantur. 2. Ut ordinatis episcopis vel clericis prius placita concilii conculcentur ab ordinatoribus eorum, ne se aliquid adversus statuta concilii fecisse adserant.

3 Cf. Statuta ecclesiae antiqua, Prologus (CCL 148, 164-166) véase nota 174.

4 HIL. PAPA, Ep. 15 o Decretum synodale Hilari papae (THIEL 161) Inscii quoque litterarum, necnon, et aliqua membrorum damna perpessi, et hi, qui ex poenitentibus sunt, ad sacros ordines adspirare non audeant.

5 ZOS. PAPA, Ep. 9, 1, 1 (SEA 106,158; PL 20, 670). Véase nota 129.

6 CAEL. I, Ep. 5, 1 (SEA 106, 178; PL 50, 436) Nulli sacerdotum suos licet canones ignorare, nec quidquam facere quod Patrum possit regulis obviare.

7 Al clero, magistrados y habitantes de Constantinopla. LEO I, Ep. 59, 1 (PL 54, 867) Nam si vix in laicis tolerabilis videtur inscitia, quanto magis in eis qui praesunt, nec excusatione est digna nec venia.

8 HIL. PAPA, Ep. 16, 4 (THIEL 168). Cuius tenore sententiae ita informati esse debetis, fratres carissimi, ut inter cetera, quae cavenda sunt, haec studeatis praecipue custodiri, quae cognoscitis ante universa mandari. In quibus etiam prospiciendum est, ne duo simul sint in una ecclesia sacerdotes, nec litteratus ignarus, aut carens aliqua parte membrorum, vel etiam ex poenitentibus aliquis ad sacrum ministerium prorsus sinatur accedere.

9 GELAS., Ep. 14, 2 (SEA 106, 200; THIEL 362-363) Ut si quis ad clericale munus accedit [...] inquiratur [...] si assecutus est litteras. GELAS., Ep. 14, 3 (SEA 106, 202-204; THIEL 364) Nec fas esse confidat quisque pontificum [...] sine litteris [...] divinis servituros applicare mysteriis. GELAS., Ep. 14, 16 (SEA 106, 212; THIEL 371-372) Illitteratos quoque et nonnulla parte corporis imminutos sine ullo respectu ad ecclesiasticum didicimus venire servitium. Quod simul antiqua traditio et apostolicae sedis vetus forma non recipit; quia nec litteris carens sacris esse potest aptus officiis, et vitiosum nibil prorsus Deo offerri legalia praecepta sanxerunt. Itaque de cetero modis omnibus haec vitentur, nec quisquam talis suscipiatur in clerum. Si qui vero vel temeritate propria vel incuria praesidentium tales ante suscepti sunt, in his, quibus constituti sunt, locis eatenus perseverent, ut nibil unquam promotionis arripiant, satisque habeant, hoc ipsum sibi pro nimia miseratione permissum. 
Esta formación no solo se refería a una instrucción elemental, sino también a una formación específica en temas sagrados. Hay, por lo tanto, una distinción implícita entre la formación cultural que los clérigos podían tener en común con el resto de sus contemporáneos y la formación eminentemente eclesiástica que necesitaban para desempeñar su ministerio pastoral. Conviene analizar entonces esta distinción.

\section{Formación intelectual del clero}

En el siglo IV, en el Imperio romano la educación se llevaba a cabo por medio de escuelas públicas y también por las escuelas privadas, fundadas por iniciativa personal de algunos profesores, como ocurría en Roma por ejemplo ${ }^{10}$.

La cultura de este tiempo era esencialmente literaria, fundada sobre la gramática y la retórica, por lo que la instrucción recibida entonces tendía a realizar en el estudiante el tipo ideal del orador ${ }^{11}$. Tal educación continuaba la línea tradicional de tiempos de Cicerón o Quintiliano ${ }^{12}$ y esta cultura tradicional continúa aún después de Agustín y se conserva incluso en Sidonio Apolinar en las Galias en el siglo quinto y en Enodio y Fortunato en Italia en el siglo sexto ${ }^{13}$.

El contenido de la formación intelectual consistía básicamente en una larga serie de estudios, según el esquema de enseñanza helenísticoromano $^{14}$, que finalizaba recién hacia los veinte años ${ }^{15}$. Los primeros años

10 Cf. H. I. Marrou, Storia dell'educazione nell'antichità (Roma $\left.{ }^{2} 1966\right)$ 398-402.

11 H. I. Marrou [Cf. H. I. Marrou, Saint Augustin et la fin de la culture antique (Paris 1938) 4] estudió a Agustín para llegar a comprender cuál era la formación que recibía una persona instruida en el siglo $\mathrm{V}$ ya que sostiene que la misma tiene una base común con la de los intelectuales de finales del siglo IV, cristianos o paganos, como Ambrosio, Jerónimo, Símaco o Ausonio. Además B. Studer [Cf. B. STuder, Eruditio veterum, en Storia della teologia I. Epoca patristica (Casale Monferrato 1993) 334] considera asimismo que en el cuarto y quinto siglo el encuentro entre el cristianismo y la antigüedad se ha desarrollado sobre todo a nivel literario y además sostiene que el objetivo de la escuela antigua era formar al hombre político, es decir a los futuros magistrados y gobernadores. Aquellos que tenían una buena formación obtenían más fácilmente un puesto en la administración pública.

12 Cf. J. Bowen, Storia dell'educazione occidentale. Vol. I (Milano 1979) 350.

13 Cf. H. I. Marrou, Saint Augustin et la fin de la culture antique (Paris 1938) 5; véase también la nota al pie n. 2 en la misma página) y 10.

14 Cf. H. Drobner, Manual de patrología (Barcelona 1999) 145.

15 Cf. H. I. Marrou, Saint Augustin et la fin de la culture antique (Paris 1938) 10. 
equivalían a una escuela primaria donde se aprendía la lectura, la escritura y los cálculos prácticos impartidos por el litterator/ludi magister, posteriormente se continuaba con los estudios liberales, que estaban divididos en dos ciclos sucesivos: en el primero el grammaticus enseñaba la gramática (primera de las artes liberales), instruyendo en sus fundamentos y haciendo conocer los principales autores clásicos (Terencio, Horacio, Ovidio, Tibulio, Lucanio, Eustacio, Cicerón, Salustio, César y Virgilio $^{16}$ ) a los cuales comentaba literalmente (enarratio auctorum). Además, partiendo de las alusiones históricas, jurídicas o científicas contenidas en los pasajes que se explicaban, el profesor iniciaba a los alumnos en las diferentes áreas del saber antiguo y les impartía una buena cultura general ${ }^{17}$. En el segundo ciclo el rethor enseñaba la retórica, consistente en las reglas y los procedimientos del discurso (topoi, dispositio, elocutio, actio). Además, en esta etapa de la formación se aprendía la dialéctica y las artes liberales restantes, es decir aritmética, música, geometría y astronomía. Una vez finalizados estos estudios el sujeto podía convertirse en un orador, un político o comenzar la escuela de derecho para transformarse en abogado ${ }^{18}$.

Si bien estos eran los fundamentos escolares comunes en la antigüedad cristiana, la educación recibida por aquellos que pertenecían a la clase aristocrática (p.ej., Ambrosio y Mario Victorino), podía ser aún más amplia ya que implicaba también conocimientos de filosofía, ciencias naturales, medicina y arquitectura ${ }^{19}$.

Dado que en el siglo IV la enseñanza de la cultura general era brindada solo por las escuelas públicas del Imperio ${ }^{20}$ los cristianos frecuentaban es-

16 Cf. P. Riché, Éducation et culture dans l'Occident barbare. VI-VIII siècles (Paris 1962) 25.

17 Cf. P. Riché, Éducation et culture dans l'Occident barbare. VI-VIII siècles, 41-42.

18 Cf. P. Riché, Éducation et culture dans l'Occident barbare. VI-VIII siècles, 43-44.

19 Cf. M. Zelzer, «Appunti su Ambrogio e le discipline scientifico-naturali» SEA 101 (2007) 357-362. Este autor estudió a Ambrosio de Milán para fundamentar su afirmación, y también trae a colación el caso de Mario Victorino

20 Cf. R. LeBel, «La formation intellectuelle et pastorale des prêtres au grand siècle patristique» en Travaux Du Congres De La Société Canadienne De Théologie, Le prêtre hier aujourd'hui demain (Ottawa 1970) 108-109. 
tas instituciones ${ }^{21} \mathrm{y}$ eran educados por maestros paganos ${ }^{22}$. Aquellos que ingresaban al clero, por lo tanto, habían adquirido la cultura profana concurriendo a las escuelas públicas imperiales ${ }^{23}$. Asimismo, algunos autores conocidos del cristianismo habían concurrido a los centros culturales más importantes de su tiempo (por ejemplo, Basilio y Gregorio asistieron a la universidad de Atenas) o habían estudiado con maestros paganos (Juan Crisóstomo y Teodoro de Mopsuestia estudiaron con Libanio, famoso profesor de retórica; Jerónimo escuchaba a Donato en Roma). Además, los cristianos no solo se educaban en las escuelas públicas del Imperio, sino que, desde el 250 en adelante, algunos incluso enseñaban en ellas ${ }^{24}$. Entre los profesores cristianos se puede mencionar a Lactancio, Gregorio de Nisa y Agustín. Los cristianos, por tanto, siguen frecuentando las escuelas públicas y no se oponen al sistema de educación en vigor, sino al espíritu pagano de la misma educación ${ }^{25}$. También muchos autores cristianos usaron los esquemas de su educación clásica para componer sus escritos, para comentar la sagrada Escritura ${ }^{26}$ y los predicadores se valían de los esquemas de la retórica para pronunciar sus sermones. De esta forma se fue realizando un acercamiento entre las culturas pagana y cristiana en la formación de los clérigos ${ }^{27}$.

\section{La formación eclesiástica del clero}

Los ministros de la Iglesia necesitaban, además de la formación humanística, una preparación específicamente eclesiástica para desempeñar ade-

21 Di Berardino [Cf. A. Di Berardino, «Maestri cristiani nel III secolo» Augustinianum 12 (1972) 549, nota 1] trae a colación el caso del graffito descubierto en el Palatino, donde habría funcionado una escuela pública, el cual representa a un hombre crucificado con cabeza de burro, que sería una burla hecha por los alumnos paganos a un compañero cristiano que frecuentaba la misma escuela. Cf. también B. STUDER, «Eruditio veterum» en Storia della teologia I. Epoca patristica (Casale Monferrato 1993) 334-335.

22 Cf. B. AmatA, voz Scuola en NDPAC III, 4817.

23 Cf. V. Grossi-A. Di Berardino, La chiesa antica: ecclesiologia e istituzioni, 89.

24 A. Di Berardino, «Maestri cristiani nel III secolo», 549-556.

25 Cf. P.H. LAFOnTAINe, Les conditions positives de l'accession aux ordres dans la première législation ecclésiastique (300-492) (Ottawa 1963) 229.

26 Cf. R. LeBEL, La formation intellectuelle et pastorale des prêtres an grand siècle patristique, 107. 109.

27 Cf. P. Riché, Éducation et culture dans l'Occident barbare. VI-VIII siècles, 121-122. 
cuadamente su ministerio. Sin embargo, según diversos estudios, en el siglo $\mathrm{V}$ todavía no existía ninguna institución preparada para ese fin.

Se conocen en Occidente casos ilustres de algunos que fueron elevados al episcopado sin una preparación eclesiástica previa (Ambrosio, Agustín), pero esto no representaba la generalidad y la Iglesia comienza a poner cada vez más esmero en establecer un proceso de formación para aquellos que deben ser destinados al clero superior.

No hay pruebas de que la Iglesia haya organizado una enseñanza propiamente eclesiástica hasta el siglo $\mathrm{V}$, por lo cual carecía de estructuras organizadas para la preparación específica en los candidatos al sacerdo$\mathrm{cio}^{28}$. Solo en el siglo VI habrían comenzado a conformarse las llamadas escuelas episcopales, donde el obispo junto con algunos presbíteros tenía la tarea de iniciar a los jóvenes en la vida sacerdotal, comenzando con los lectores ${ }^{29}$.

De todos modos, aunque no existieran estructuras educativas específicas, los clérigos eran formados de modo personalizado y vivencial observando y escuchando al obispo y a los sacerdotes más experimentados del presbiterio que estaban con él, con el estudio personal y el ejercicio de las órdenes recibidas y a través de la práctica de los sacramentos. El futuro clérigo, frecuentemente desde la adolescencia en calidad de lector, convivía con sus maestros y así acababa por actuar y expresarse como ellos $^{30}$. A pesar de todo esto, aquellos que eran llamados repentinamente

28 Cf. G. BARDY, «Le sacerdoce chrétien du Ier au Ve siècle» en G. BARDy y otros, Prêtres d'bier et aujourd'bui, (Paris 1954) 41; P. RichÉ, Éducation et culture dans l'Occident barbare. VI-VIII siècles, 170; H. I. MArrou, Storia dell'educazione nell'antichità, 425, 428 y 436; V. Grossi - A. Di Berardino, La chiesa antica: ecclesiologia e istituzioni, 90.

29 Sobre el argumento de las escuelas parroquiales Cf. P. RichÉ, Éducation et culture dans l'Occident barbare. VI-VIII siècles, 163-171; P.H. LAFONTAINE, Les conditions positives de l'accession aux ordres dans la première législation ecclésiastique (300-492), 222; H. I. MARrou, Storia dell'educazione nell'antichità, 436; P. Riché, Les écoles et l'enseignement dans l'Occident chrétien de la fin du V siècle au milieu du XI siècle (Paris 1979) 39-40.

30 Cf. G. Jouassard, Pour une étude du sacerdoce au temps des pères, en La tradition sacerdotale. Etudes sur le sacerdoce (Lyon 1959) 116; H. I. MARrou, Storia dell'educazione nell'antichità (Roma $\left.{ }^{2} 1966\right)$ 428; V. Grossi - A. Di Berardino, La chiesa antica: ecclesiologia e istituzioni, 89; R. LEBEL, La formation intellectuelle et pastorale des prêtres au grand siècle patristique, 111. Según una carta de Jerónimo, el presbítero Nepociano fue educado por su tío que era Pontifex Christi Cf. Hier., Ep. 52 (PL 22, 530). Scio quidem ab auunculo tuo, beato Heliodoro, qui nunc pontifex Christi est, te et didicisse quae sancta sunt, et cotidie discere normamque vitae eius exemplum habere virtutum [...]. 
al ministerio presbiteral o episcopal debían formarse solamente con la misma práctica pastoral, como por ejemplo Agustín ${ }^{31}$, Pauliniano, Paulino de Nola, Jerónimo en Antioquia.

Algunos obispos, para llevar a cabo esta tarea formativa, agruparon en torno a sí a los presbíteros, como Hilario de Poitiers que fundó un colegio presbiteral (después del 350) con un grupo de presbíteros y de clérigos para hacer vida en común e instruirlos ${ }^{32}$. O la comunidad monástica clerical fundada por Eusebio de Vercelli donde sus miembros se dedicaban a la oración, el estudio y la vida pastoral y el «monasterium clericorum» fundado por Agustín en la ciudad de Hipona ${ }^{33}$, donde el clero era formado en la vida común, el estudio y el ministerio. Los presbíteros de Arles $^{34}$ vivían en común con su obispo Cesario (470 aprox.-543) que los formaba en la oración y en las Escrituras ${ }^{35}$. En la iglesia de las Galias en el año 529 $9^{36}$,

31 Agustín pide a su obispo Valerio que le dé un tiempo para instruirse en las sagradas escrituras (AUG., Ep. 21 -PL 33, 88-89). Respecto a la formación que el clérigo adquiría en base a la propia experiencia en el ejercicio del ministerio, en la misma carta Agustín dice: (Ep. 21, 3 -PL 33, 89) Quod si propterea in re ipsa didici quid sit homini necessarium, qui populo ministrat sacramentum et verbum Dei.

32 Cf. A. G. Hamman, «La formation du clergé latin, dans les quatre premiers siècles» en SP 20 (1989) 247-249.

33 Cf. AUG., Serm. 355 y 356 [C. Lambot, en Strom. Patr. et Med., I (Utrecht 1950) 12343].

34 Cf. P. Riché, Éducation et culture dans l'Occident barbare. VI-VIII siècles, 166-168.

35 Vita Caesarii, I, 15 (Morin ed., II, 301) De profectibus itaque cunctorum sollicitus et providus pastor statim instituit, ut cotidie tertiae sextae et nonae opus in sancti Stephani basilica clerici cum bymnis cantarent [...]; ibid., I, 52 (MORIN ed., II, 317) In disserendis autem scripturis et in elucidandis obscuritatis quanta gratia in illo emicuerit, quis potere enarrare?[...]; Ibid., I, 56 (MORIN ed., II, 320) Adiecti etiam hoc, ut nunquam in ecclesia sua diaconum ordinaret ante tricesimum aetatis eius annum. Verum etiam et hoc addidit, ut nec in qualibet maiore aetate umquam ordinaretur, nisi quattuor vicibus in ordine libros veteris testamenti legerit, et quattuor novum [...]; ibid., I, 62 (Morin ed., II, 322) Ad prandium vero et ad cenam mensae suae sine cessatione cotidie legebatur, ut uterque interior exteriorque homo satiatus refectione duplici laetaretur [...]; ibid., II, 31 (Morin ed., II, 337-338) Nam illud quam sanctum et dulce erat, cum per diem incessabiliter oportune inportune, volentibus nolentibus, verbum dei ingereret! Cum iam vero pausare veniret, ut vel ipsius horae momento de scripturis divinis et de instructione sancta non vacaret, aiebat ad nos: "dicite me, inquit, quid cenavimus hodie, qualia fercula habimus?»Nos tacentes suspirabamus, quia illuc intellectus noster ducebatur, quo ille solitus erat nos provocare, quod de cibo spirituali loqui volebat, et ideo nos interrogaret [...]; ibid., I, 56 (MorIN ed., II, 320).

36 Conc. Vanense (529) c. 1 (CCL 148 A, 78) Hoc placuit, ut omnes presbyteri, qui sunt in parrociis constituti, secundum consuetudinem, quam per totam Italiam satis salubriter teneri cognovemus, iuniores lectores, quantoscumque sine uxoribus habuerent, secum in domo, ubi ipsi habitare viden- 
asumieron una costumbre de Italia que consistía en que los presbíteros recibían en sus parroquias a los lectores jóvenes para instruirlos en las ciencias sagradas, en las Escrituras, en la oración con los salmos y prepararlos como sus sucesores. En la iglesia de España ${ }^{37}$ en el siglo VI se establece que los niños que han sido consagrados para el clero por sus padres sean formados por el obispo conviviendo con él y después recibir los distintos ministerios y ser ordenados sacerdotes.

En Italia la formación eclesiástica estaba estructurada en base al cursus ecclesiasticus ${ }^{38}$, que era un tiempo articulado en etapas, grados y ministerios, durante los cuales se educaba y se examinaba al candidato y este se entrenaba durante un tiempo (interstitia) en las distintas órdenes menores (stipendium, officium) hasta llegar a la consagración presbiteral o episcopal. Dado que este era el sistema propio para preparar a los candidatos para el sacerdocio sería equivocado pretender encontrar, al menos hasta fines del siglo $\mathrm{V}$, instituciones específicas para la formación del clero.

Respecto al contenido de la formación eclesiástica que debían recibir los futuros pastores la información no es muy abundante. De todos modos, por las fuentes disciplinares de las iglesias de África ${ }^{39}$, de las Galias ${ }^{40}$ y de Roma ${ }^{41}$ y por algunos decretos papales ${ }^{42}$ de los siglos IV y V se puede

tur, recipiant et eos quomodo boni patres spiritaliter nutrientes psalmis parare, divinis lectionibus insistere et in lege Domini erudire contendant, ut et sibi dignos successores provideant et a Domino proemia aeterna recipiant. Cum vero ad aetatem perfectam pervenerint, si alequis eorum pro carnis fragilitate uxorem habere voluerit, potestas ei ducendi coniugium non negetur.

37 Concilium Toletanum II, 1 [G. MARTínez - F. RodrígueZ, La colección canónica bispana IV (Madrid 1984) 347-348] De his quos voluntas parentum a primis infantiae annis clericatos officio manciparit, statuimus observandum ut mox detonsi vel ministerio electorum contraditi fuerint, in domo ecclesiae sub episcopali praesentia a praeposito sibi debeant erudiri (...).

38 Cf. P.H. Lafontaine, Les conditions positives de l'accession aux ordres dans la première législation ecclésiastique (300-492), 235; A. FAIVRE, Naissance d'une biérarchie. Les premières étapes du cursus clérical, 316, nota 28; J. Sт. H. Gibaut, The Cursus Honorum. A Study of the Origins and Evolution of Sequential Ordination (New York 2003) 153.

39 Cf. Concilio de Cartago del 397. Breviarium hipponense cc. 1c y 2 (CCL 149, 33) Véase nota 199.

40 Statuta ecclesiae antiqua (CCL 148, 164-166). Véase nota 174.

41 Cf. Sínodo de Roma del 465, HIL. PAPA, Ep. 15 o Decretum synodale Hilari papae (THIEL 161). Véase nota 201.

42 ZOS. PAPA, Ep. 9, 1, 1 (SEA 106, 158; PL 20, 670) [...]Ne quis penitus contra patrum preacepta, qui ecclesiasticis disciplinis per ordinem non fuisset imbutus, et temporis approbatione divinis stipendiis eruditus, nequaquam ad summum Ecclesiae sacerdotium aspirare praesumeret. 
saber que a los sacerdotes se les exigía conocer las disposiciones de los concilios, los cánones que se refieren al sacerdocio, las sagradas Escrituras y su recta interpretación, las disciplinas eclesiásticas, los dogmas de la Iglesia.

Tampoco la documentación pontificia de ese tiempo respecto a la preparación de los clérigos es muy precisa en relación a la formación eminentemente eclesiástica de los mismos, pero esto podría significar también que en ese momento se ponía más atención en el aspecto moral de la persona y en el buen ejercicio del ministerio que en la adquisición de conocimientos intelectuales ${ }^{43}$.

\section{Conclusión}

En base a la investigación realizada sobre la formación de los clérigos en el siglo $\mathrm{V}$ en la Iglesia occidental se concluye, en primer lugar, que en el siglo $\mathrm{V}$ se requería ser una persona instruida para acceder al presbiterado.

En este tiempo los candidatos al clero tenían posibilidades concretas de adquirir una buena educación profana basada especialmente en la gramática y la retórica en las escuelas públicas existentes en el territorio del Imperio.

En segundo lugar, la formación específicamente eclesiástica necesaria en los clérigos para el desempeño de su ministerio se realizaba, al menos en las diócesis donde el obispo se preocupaba por la formación de sus ministros, a través de una formación personalizada a través de los grados del cursus ecclesiasticus.

En tercer lugar se concluye que en la formación de los presbíteros del siglo $\mathrm{V}$ en Occidente se había producido una integración de la educación que brindaba el Imperio romano, de matriz sobre todo literaria y basada en los grandes escritores paganos, con la educación específicamente eclesiástica, fundada en las Escrituras y en los documentos conciliares. También muchos autores usaron los esquemas de su educación clásica para componer escritos cristianos y los predicadores se valían de la retórica para pronunciar sus sermones. En la Iglesia en Occidente hacia el siglo V no se despreciaba, por lo tanto, la formación clásica sino que se la tomaba como parte imprescindible en la formación de los ministros ordenados.

CAEL. I, Ep. 5, 1 (PL 50, 436) Nulli sacerdotum suos licet canones ignorare, nec quidquam facere quod Patrum possit regulis obviare.

43 Cf. A. Di Berardino, «Clerus» en NDPAC I, 1087-1088. 
Resumen: Este artículo investiga cómo la conjunción entre fe y razón formaba parte, en la Iglesia de Occidente del siglo V, de la formación exigida a los presbíteros encargados de las comunidades. Este trabajo se articula en tres partes: la primera muestra cómo, en el siglo $\mathrm{V}$, la formación intelectual era un requisito ya tradicionalmente exigido a los candidatos al ministerio ordenado; la segunda expone cuáles eran los estudios humanísticos que ellos podían realizar en su tiempo y, la tercera, trata sobre la formación eminentemente sacerdotal que los preparaba para desempeñar su ministerio en las comunidades que se les confiaban.

Palabras clave: Formación sacerdotal, patrística, Occidente.

Abstract: This article investigates how the combination of faith and reason formed part of the training required for the presbyters in charge of the communities in the Western Church of the $5^{\text {th }}$ century. The present study is organized in three parts: the first shows how, in the 5 th century, intellectual training was already traditionally required for candidates for the ordained ministry; the second shows what humanistic studies they could carry out in their time, and the third deals with the eminently priestly formation that prepared them for ministry in the communities entrusted to them.

Key words: Priestly formation, patristic, Western. 